\title{
Farklı Anaçlar Üzerine Aşılanan Kırkağaç Kavunlarının Meyve Özelliklerinin Araştırılması
}

\begin{abstract}
ÖZ
Mihriban NAMLI ${ }^{1}$, Serkan KASAPOGLU ${ }^{1}$, İlknur SOLMAZ ${ }^{1}$

$\mathrm{Bu}$ çalışmada aşılamanın meyve özellikleri üzerine etkisini incelemek amacıyla, Ares F1, Nun 9075 F1 ve TZ 148 F1 olmak üzere 3 adet Cucurbita hibrit (C. maxima Duch. x C. moschata Duch.) anac1 kullanılmıştır. $\mathrm{Bu}$ anaçlar üzerine kalem olarak ülkemizde ticari olarak yetiştiriciliği yapılan Kırkağaç tipi Sinem 45 F1 ve Sürmeli F1 (Cucumis melo L. var. inodorus; Verim, Ziraat) aşılanmışıtır. Sinem 45 F1 ve Sürmeli F1 kavun çeşitleri kendi üzerine de aşılanmış olup, aşısız bitkileri ise kontrol olarak kullanılmıştır. Çalışmada meyve ağırlığı $(\mathrm{g})$, meyve yüksekliği $(\mathrm{cm})$, meyve çapı $(\mathrm{cm})$, çekirdek evi yüksekliği $(\mathrm{cm})$, çekirdek evi çapı $(\mathrm{cm})$, meyve eti kalınlığ $(\mathrm{cm})$, meyve kabuk kalınlığı $(\mathrm{mm})$ ve SÇKM (\%) değerleri incelenmiştir. Araştırma bulgularına göre, incelenen parametreler açısından Sinem $45 \mathrm{~F}$ ç çeşidi Sürmeli $\mathrm{F}_{1}$ çeşidinden daha iyi değerlere sahip olmuştur. Meyve ağırlığ (4200, 4120 g), meyve yüksekliği $(32.72,34.98 \mathrm{~cm})$, çekirdek evi yüksekliği $(22.67,22.44 \mathrm{~cm})$, meyve kabuk kalınlığı (13.61 mm) değerleri incelendiğinde, Ares F1 ve TZ 148 F1 anacı üzerine aşılı Sinem F1 çeşidinde en yüksek değerler tespit edilirken, meyve ağırlı̆ıında $(2030 \mathrm{~g})$, meyve yükseliğinde $(21.33 \mathrm{~cm})$, meyve çapında $(13.67 \mathrm{~cm})$, meyve eti kalınlığında $(4.17 \mathrm{~cm})$ en düşük değerler Nun 9075 anacı üzerine aşılı Sürmeli Fı çeşidinden elde edilmiştir. Suda çözünebilir kuru madde içeriği en yüksek kontrol Sinem F1 çeşidi, kontrol Sürmeli F1 çeşidi ve Ares F1 anacı üzerine aşılı Sürmeli F1 çeşidinden ( \%10.24, \%9.87 ve \%9.97) elde edilmiştir.
\end{abstract}

Anahtar Kelimeler: Cucumis melo L., kavun aşılama, Kırkağaç, kalite

\section{Investigation of Fruit Quality Traits of Kırkağaç Melons Grafted on Different Rootstocks}

\begin{abstract}
In this study, three Cucurbita hybrid (C. maxima Duch. X C. moschata Duch.) rootstocks, namely Ares $\mathrm{F}_{1}$, Nun $9075 \mathrm{~F}_{1}$ and TZ $148 \mathrm{~F}$, were used to examine the effect of grafting on fruit characteristics. Kırkağaç type Sinem 45 F1 and Sürmeli F1 (Cucumis melo L. var. inodorus; Verim Ziraat), which are grown commercially in Turkey, were grafted on these rootstocks. Sinem 45 F1 and Sürmeli F1 melon varieties were also grafted on themselves, and ungrafted plants were used as control. In the study, fruit weight $(\mathrm{g})$, fruit height $(\mathrm{cm})$, fruit diameter $(\mathrm{cm})$, fruit cavity height $(\mathrm{cm})$, fruit cavity diameter $(\mathrm{cm})$, fruit flesh thickness $(\mathrm{cm})$, fruit rind thickness $(\mathrm{mm})$ and TSS $(\%)$ values have been examined. According to the research results, Sinem $45 \mathrm{~F}_{1}$ variety had better values than Sürmeli F1 variety in terms of examined parameters. When the values of fruit weight $(4200,4120$ $\mathrm{g})$, fruit height $(32.72,34.98 \mathrm{~cm})$, fruit cavity height $(22.67,22.44 \mathrm{~cm})$, fruit rind thickness $(13.61$ $\mathrm{mm}$ ) are examined, the highest values were determined from Sinem F1 variety grafted on Ares $F_{1}$ and TZ $148 \mathrm{~F} 1$ rootstocks, the lowest values in fruit weight $(2030 \mathrm{~g})$, fruit height $(21.33 \mathrm{~cm})$, fruit diameter $(13.67 \mathrm{~cm})$, fruit flesh thickness $(4.17 \mathrm{~cm})$ were obtained from Sürmeli F1 variety grafted on Nun 9075 rootstock. The highest total soluble solid content was obtained from ungrafted Sürmeli $F_{1}$ and Sinem $F_{1}$ variety and the Sürmeli $F_{1}$ variety grafted on the Ares F1 rootstock (\%10.24, \%9.87, \%9.97).
\end{abstract}

Keywords: Cucumis melo L, melon grafting, Kirkagac, quality

ORCID ID (Yazar sirasina göre)

0000-0003-2474-7494, 0000-0002-4153-8910, 0000-0003-2996-0286

Yayın Kuruluna Geliş Tarihi: 27.10.2021

Kabul Tarihi: 22.12.2021

${ }^{1}$ Çukurova Üniversitesi, Ziraat Fakültesi, Bahçe Bitkileri Bölümü, Adana, Türkiye

*E-posta: mihribannamli46@gmail.com 


\section{Farklı Anaçlar Üzerine Aşılanan Kırkağaç Kavunlarının Meyve Özelliklerinin Araştırılması}

\section{Giriş}

Kavun (Cucumis melo L.) Cucurbitaceae familyası içerisinde kültüre alınmıș, ekonomik önemi fazla ve üretimi geniş alanlarda yapılan bir sebzedir. Dünyadaki toplam üretimi 1.039.691 ha alanda 27.501.360 tondur (FAO, 2020). Kavun (Cucumis melo L.) Cucumis cinsi içerinde meyve şekli ve boyutu bakımından en fazla çeşitlilik gösteren türdür ve Cucumis melo subsp. melo ve Cucumis melo subsp. agrestis olmak üzere 2 alt türe ayrılmaktadır (Pitrat, 2008). Kavun yetiştiriciliği ülkemizde, daha çok açıkta ve Cucumis melo L. var. inodorus tipine giren iri meyveli, kokusuz ve uzun raf ömrüne sahip Kırkağaç, Yuva ve Hasanbey gibi çeşitlerle yapılmaktadır. Bunlar arasında, şekil ve boyut açısından çeşitlilik gösteren Kırkağaç kavunu sarı zemin üzerine siyah benek ve noktalara sahip meyveleriyle en fazla üretim payına sahiptir (Mancak ve ark., 2014). Türkiye'de kavun üretiminde, Fusarium oxysporum f.sp. melonis çok büyük ekonomik kayılara neden olmaktadır. Bu patojen ile mücadelede en etkili yöntem olarak dayanıklı çeşitler kullanmak ön plana çıkmaktadır. Ülkemizde bazı bölgelerde Fusarium oxysporum f.sp. melonis in 1, 1-2 ve 0 no'lu rklar1 (Ege Bölgesi), bazı bölgelerde ise 0, 1, 2, 1-2 1rkları (Güneydoğu Anadolu Bölgesi) yapılan çalışmalar sonucunda tespit edilmiştir (Şensoy, 2005). Son yıllarda dünyada ve ülkemizde kavun üretiminde aşılı fide kullanımının bu patojene karşı mücadelede önemli bir alternatif olacağı düşünülmektedir. Bitkileri dayanıklı anaçlar üzerine aşılamak, mantar hastalıkları, nematodlar, kuraklık, tuzluluk ve aşırı sıcaklıklar gibi biyotik ve abiyotik streslerle başa çıkmak için dünya çapında yaygın olarak kullanılan kültürel bir uygulamadır (Davis ve ark., 2008). Biyotik ve abiyotik streslere toleranslarının yanı sira hibrit Cucurbita anaçları, iyi çıkıs performansı göstermeleri ve aşılamay1 kolaylaştıran uzun ve kalın hipokotiller geliştirmeleri nedeniyle tercih edilmektedir. Ancak, bu melezlerin bazı önemli eksiklikleri vardır. Aşırı güçlü olmaları, aşı1ı bitkilerde çiçeklenme ve olgunlaşma süreçlerinde gecikmeye neden olabilir (Soteriou ve ark., 2016), nematodlara dirençli değillerdir (Cohen ve ark., 2014; Özarslandan ve ark., 2011) ve genellikle meyve kalitesi üzerinde olumsuz etkileri vardır (Guan ve ark., 2015; Rouphael ve ark., 2010; Soteriou ve ark., 2014). Kalite üzerindeki bu etkiler, anaç-kalem etkileşimlerine bağlıdır. Kavunda (Cucumis melo L.), örneğin, meyve büyüklügünde ve çekirdek evinde bir artış (Verzera ve ark., 2014) veya meyve eti sertliğindeki değişiklikler (Colla ve ark., 2006; Zhao ve ark., 2011) aşılama sonucunda yaygın olarak görülmektedir. Et rengi varyasyonları (Colla ve ark., 2006), camlaşma (Jang ve ark., 2014), pH ve suda çözünebilir kuru madde içeriğindeki değișiklikler (Colla ve ark., 2006; Verzera ve ark., 2014) de rapor edilmiştir. Ancak farklı anaçların Kırkağaç kavununa anaçlık potansiyelini belirleme amaciyla yapılmış herhangi bir çalışma bulunmamaktadır. Yapılan bu çalışmada, ülkemizde yoğun olarak yetiştiriciliği yapılan Cucumis melo $\mathrm{L}$. var. inodorus türüne ait Kırkağaç kavunlarının, $C$. maxima x C. moschata grubuna ait farklı anaçlar üzerine aşılanarak meyve kalite özellikleri araştırılmıştır.

\section{Materyal ve Yöntem}

Bu çalışmada, Cucurbita hibrit (C. maxima Duch. x C. moschata Duch.) grubuna ait 3 adet anaç (Ares, Nun9075, TZ148) kullanılmıştır. Bu anaçlar üzerine kalem olarak, ülkemizde ticari olarak yetiştiriciliği yapılan Kırkağaç tipi Sinem 45 F1 ve Sürmeli F1 (Cucumis melo L. var. inodorus; Verim Ziraat) aşılanmıştır. Sinem 45 F1 ve Sürmeli F1 kavun çeşitlerini aşısız bitkileri ise kontrol olarak kullanılmıştır. Tohumlar 15.03.2020 tarihinde ekilmiş, aşılamalar 05.04.2020 tarihinde yapılmıştır. Dikim büyüklüğüne gelen fideler, aşı yerleri toprak üzerinde kalacak şekilde, sıra arası ve sıra üzeri $200 \times 90 \mathrm{~cm}$ aralıklarla, tesadüf blokları deneme deseninde ve 3 tekerrür, her tekerrürde 10 bitki olacak şekilde (toplamda 240 adet aş11 fide, 60 adet aşısız fide) alçak plastik tünel içerisine 20.04.2020 tarihinde dikilmiştir. Damlama sulama sistemi kullanılmış olup, topraktan gübreleme yine damlama sulama sistemi aracılığıyla yapılmıştır. Yabancı ot kontrolü için siyah renkli malç kullanılmıştır. Fungal ve bakteriyel hastalıklar ile zararlılara karşı, kimyasal mücadele yöntemi uygulanmıştır. Hasat olgunluğuna gelen meyveler, 15.07.2020 


\section{Farklı Anaçlar Üzerine Aşılanan Kırkağaç Kavunlarının Meyve Özelliklerinin Araştırılması}

tarihinde hasat edilmiş ve her tekerrürden 5 meyvede meyve ağırlığı terazi yardımıyla; meyve yüksekliği, meyve çapı, çekirdek evi yüksekliği, çekirdek evi çapı, meyve eti kalınlığı cetvel yardımıyla; meyve kabuk kalınlığ 1 dijital kumpas ile ve SÇKM dijital refraktometre yardımıyla ölçülmüştür. Çalışma sonucunda elde edilen veriler JMP v.9 istatistiksel paket programında 'Tesadüf Blokları' deneme desenine göre varyans analizine tabi tutulmuştur. Varyans analizi sonucuna göre, faktörlere ait ortalamalar önem seviyelerine göre karşılaştırılmışlardır.

\section{Bulgular ve Tartışma}

Sebzelerin dayanıklı anaçlar üzerine aşılanması, biyotik ve abiyotik streslere karşı etkili bir yöntem olmakla birlikte aynı zamanda verimde de stabiliteyi sağlamaktadır (Rouphael ve ark., 2018). Den Nijs (1984) tarafindan, aş1lamanın bitki boyu ve yaprak sayısını arttırmasının anaç ve kaleme bağlı olarak değiştiği, ayrıca kuvvetli kök yapısına sahip anaç kullanımının, gövde kalınlığını ve bitki boyunu da artırdığ bildirilmiştir. Cucurbitaceae familyasına ait türler, bu teknikte anaç olarak yaygın şekilde kullanılmaktadır (Gaion ve ark., 2018). Ülkemizde yoğun olarak yetiştiriciliği yapılan Cucumis melo L. var. inodorus türüne ait Kırkağaç kavunlarının, farklı Cucurbita hibrit (C. maxima x C. moschata) anaçları üzerine aşılanarak meyve kalite özelliklerinin araştırılması amacıyla yapılan çalışmada; incelenen parametreler açısından Sinem 45 F1 çeşidi Sürmeli F1 çeşidinden daha iyi değerlere sahip olmuştur. Meyve büyüklügü, hem tüketiciler tarafindan oldukça önem verilen hem de verimle ilișkili parametrelerden biridir. Uyumsuzluk olmaması koşuluyla, çok sayıda anaç-kalem kombinasyonu için aşılama sonucunda, önemli verim artışları yaygın olarak rapor edilmiștir (Yetisir ve Sari, 2003; Yetisir ve ark., 2003; Huitrón ve ark., 2007; Cushman ve Huan, 2008). Yapilan analizlerde ortalama meyve ağırlığı en fazla Ares F1 üzerine aşılanan Sinem 45 F1 çeşidinden elde edilirken (4200 g), bu değeri $\mathrm{TZ} 148 \mathrm{~F} 1$ anac1 üzerine aşılanan Sinem 45 F1 çeşidi $(4120 \mathrm{~g})$ takip etmiştir. En düşük meyve ağırlığı (2030 g) ise Nun 9075 F1 anacı üzerine aş1lı Sürmeli F1 çeşidinden alınmıştır. Sinem 45 F1 çeşidinin ortalama meyve ağırlı̆̆ 1 (3900 g), Sürmeli F1 çeşidinden $(2430 \mathrm{~g})$ daha yüksek bulunmuştur (Çizelge 1). Nisini ve ark. (2002), kavunda aşılamanın hem $F$. oxysporum'un 1 ve 2 nolu irklarına dayanım hem de meyve kalitesi üzerine etkisini inceledikleri araştırmada, 13 adet ticari anaç ve 8 adet Cucurbit anacı kullanmışlardır. PGM 9605 ve P360 anaçları, 1,2 1rkına dirençli bulunmuş, ayrıca bu anaçlar aşı kalemi olarak kullanılan çeşitlerin meyve kalitesini önemli ölçüde iyileştirmiştir. Karabulut ve ark. (2018), Kırkağaç 589 kavun çeşidini 9 farklı kabak anacı (Siyah Çekirdekli Lif Kabağı, Kudret Narı, Beyaz Çekirdekli Lif Kabağı, Gri- Mavi Çekirdek Kabağı, Çekirdek Kabağı, Küçük Dilimli ve Turuncu Bal Kabağı, Uzun Turuncu Bal Kabağ1 ve Su Kabağı ve 1 tanesi ticari anaç TZ 148) üzerine aş1lamışlardır. Kendi üzerine aş111 ve aşısız 'Kırkağaç 589' kavun çeşidini kontrol olarak kullanmışlardır. Kullanılan anaçlar arasında, TZ 148 anacına aşılı bitkilerden en ağır $(2.8 \mathrm{~kg})$ meyveler elde edilmiştir. Elde edilen sonuçlar yapmış olduğumuz çalışmadan elde edilen bulguları destekler niteliktedir. İki çapın (yani ekvatoral ve boyuna) oranı olarak tanımlanan meyve şekil indeksi, aşılamadan potansiyel olarak etkilenen bir özelliktir. Kavunda, meyve şekil indeksinin aş1 kombinasyonlarından etkilenmediği de bildirilmiştir (Colla ve ark., 2006). Ürün verimliliğinde artış bazen bitki üzerinde ki meyve sayısı artışı ile ifade edilirken, bazen ürünün kütlesi ile ilişkilendirilmiştir. Meyve kütlesinde ki artış, meyve yüksekliği ve meyve çapını da doğru orantıda etkilemektedir. Ortalama meyve yüksekliği parametresi açısından anaç, çeşit ve anaç $\mathrm{x}$ çeşit etkileşimi istatistiksel olarak önemli bulunmuştur (Çizelge 2). $T Z 148 F_{1}$ ve Ares $F_{1}$ üzerine aşılanan Sinem F1 çeşidinin meyveleri en yüksek $(34.98 \mathrm{~cm}$, $32.72 \mathrm{~cm}$ ) bulunurken; en az meyve yüksekliği $(21.33,22.88,22.92$ ve $23.39 \mathrm{~cm})$ Sürmeli F1 çeşidinin aşı1ı ve aşısız bitkilerinden alınan meyvelerde tespit edilmiştir. Aşılamanın ortalama meyve çap1 üzerine etkisi incelendiğinde; anaçların meyve çapı üzerine etkisi istatistiksel olarak önemli bulunmuştur (Çizelge 3). En geniş meyve çapı $(17.21 \mathrm{~cm})$ Ares F1 anacı üzerine aşılı Sürmeli F1 çeşidinde 


\section{Farklı Anaçlar Üzerine Aşılanan Kırkağaç Kavunlarının Meyve Özelliklerinin Araştırılması}

bulunurken, aşısız kontrol bitkilerinde Sinem 45 F1 çeşidinin meyve çapı $16.11 \mathrm{~cm}$, Sürmeli F1 çeşidinin meyve çap1 $16.89 \mathrm{~cm}$ olmuştur. Yapılan çalışmalarda kuvvetli kök sistemine sahip anacın, aş11ı bitkilerde aşısız bitkilere göre bitki besin elementlerinin ve su alımının daha etkin olduğu belirtilmiş̧ir. Su ve besinlerin alınımındaki verimlilikleri ve etkinlikleri nedeniyle, kök gelişimini ve daha sonra ürün verimliliğinde artışı sağlamaktadır (Soteriou ve ark., 2017).

Çizelge 1. Farklı anaçlar üzerine aşılanan Sinem 45 F1 ve Sürmeli F1 çeşitlerinin ortalama meyve ağırlığ 1 (g)

\begin{tabular}{|c|c|c|c|}
\hline \multirow[t]{2}{*}{ Anaçlar } & \multicolumn{2}{|c|}{ Çeşitler } & \multirow{2}{*}{$\begin{array}{l}\text { Anaç } \\
\text { Ort. }\end{array}$} \\
\hline & $\begin{array}{l}\text { Sinem } \\
45 \mathrm{~F} 1\end{array}$ & $\begin{array}{l}\text { Sürmel } \\
\text { i F1 }\end{array}$ & \\
\hline Ares F1 & $4200 \mathrm{a}$ & $2410 \mathrm{e}$ & $\begin{array}{l}3300 \\
\mathrm{~A}\end{array}$ \\
\hline Nun 9075 F1 & $3480 \mathrm{c}$ & $2030 \mathrm{f}$ & $\begin{array}{l}2760 \\
B\end{array}$ \\
\hline TZ 148 F1 & $4120 \mathrm{a}$ & $2430 \mathrm{e}$ & $\begin{array}{l}3270 \\
\text { A }\end{array}$ \\
\hline $\begin{array}{l}\text { Aşısız } \\
\text { (Kontrol) }\end{array}$ & $3810 \mathrm{~b}$ & $2870 \mathrm{~d}$ & $\begin{array}{l}3340 \\
\text { A }\end{array}$ \\
\hline Çeşit Ort. & $3900 \mathrm{~A}$ & $2430 \mathrm{~B}$ & \\
\hline $\begin{array}{l}\text { Anaç: } 0.20^{* *} \\
\text { Anaç } \times \text { Kaler }\end{array}$ & $\begin{array}{l}\text { Kalem: } 0 \\
0.28^{* *}\end{array}$ & $4 * * *$ & \\
\hline
\end{tabular}

$\mathrm{P} \leq 0,001^{* * *}, \mathrm{P} \leq 0,01^{* *}, \mathrm{P} \leq 0,05^{*}$ düzeyinde LSD karşılaştırmasına göre farklılığı göstermektedir.

Çizelge 2. Farklı anaçlar üzerine aşılanan Sinem $45 \mathrm{~F} 1$ ve Sürmeli $\mathrm{F}$ ç̧eşitlerinin ortalama meyve yüksekliği $(\mathrm{cm})$

\begin{tabular}{|c|c|c|c|}
\hline \multirow[t]{2}{*}{ Anaçlar } & \multicolumn{2}{|c|}{ Çeșitler } & \multirow{2}{*}{$\begin{array}{l}\text { Anaç } \\
\text { Ort. }\end{array}$} \\
\hline & $\begin{array}{l}\text { Sinem } \\
45 \mathrm{~F}_{1}\end{array}$ & $\begin{array}{l}\text { Sürmeli } \\
\text { F1 }\end{array}$ & \\
\hline Ares F1 & $32.72 \mathrm{a}$ & $23.39 \mathrm{c}$ & $28.06 \mathrm{~A}$ \\
\hline $\begin{array}{l}\text { Nun } 9075 \\
\text { F1 }\end{array}$ & $29.83 \mathrm{~b}$ & $21.33 \mathrm{c}$ & $25.58 \mathrm{~B}$ \\
\hline TZ $148 \mathrm{~F} 1$ & $34.98 \mathrm{a}$ & $22.92 \mathrm{c}$ & $28.95 \mathrm{~A}$ \\
\hline $\begin{array}{l}\text { Aş1s1z } \\
\text { (Kontrol) }\end{array}$ & $28.78 \mathrm{~b}$ & $22.88 \mathrm{c}$ & $25.83 \mathrm{~B}$ \\
\hline Çeşit Ort. & $31.58 \mathrm{~A}$ & $22.63 \mathrm{~B}$ & \\
\hline $\begin{array}{l}\text { Anaç: } 1.80^{*} \\
\text { Anaç } \times \text { Kale }\end{array}$ & $\begin{array}{l}\text { * Kalem: } \\
\text { m: } 2.55^{*}\end{array}$ & $.28 * * *$ & \\
\hline
\end{tabular}

Çizelge 3. Farklı anaçlar üzerine aşılanan Sinem 45 F1 ve Sürmeli F1 çeşitlerinin ortalama meyve çap $1(\mathrm{~cm})$

\begin{tabular}{|c|c|c|c|}
\hline \multirow[t]{2}{*}{ Anaçlar } & \multicolumn{2}{|c|}{ Çeşitler } & \multirow{2}{*}{$\begin{array}{l}\text { Anaç } \\
\text { Ort. }\end{array}$} \\
\hline & $\begin{array}{l}\text { Sinem } \\
45 \mathrm{~F} 1\end{array}$ & $\begin{array}{l}\text { Sürmeli } \\
\text { F1 }\end{array}$ & \\
\hline Ares F1 & $\begin{array}{l}16.44 \\
\mathrm{abc}\end{array}$ & $17.21 \mathrm{a}$ & $16.83 \mathrm{~A}$ \\
\hline $\begin{array}{l}\text { Nun } 9075 \\
\text { F1 }\end{array}$ & $\begin{array}{l}14.33 \\
\text { de }\end{array}$ & $13.67 \mathrm{e}$ & $14.00 \mathrm{C}$ \\
\hline TZ $148 \mathrm{~F}_{1}$ & $15.68 \mathrm{c}$ & $14.77 \mathrm{~d}$ & $15.22 \mathrm{~B}$ \\
\hline $\begin{array}{l}\text { AşıS1Z } \\
\text { (Kontrol) }\end{array}$ & $\begin{array}{l}16.11 \\
\mathrm{bc}\end{array}$ & $\begin{array}{l}16.89 \\
\mathrm{ab}\end{array}$ & $16.50 \mathrm{~A}$ \\
\hline Çeşit Ort. & 15.64 & 15.63 & \\
\hline \multicolumn{4}{|c|}{$\begin{array}{l}\text { Anaç: } 0.62 * * * \text { Kalem: ÖD } \\
\text { Anac } \times \text { Kalem: } 0.87 * *\end{array}$} \\
\hline
\end{tabular}

P $\leq 0,001^{*}, P \leq 0,01^{*}, P \leq 0,05^{*}$ düzeyinde LSD

Çekirdek evinin küçük olması, meyve et randımanın fazlalığı açısından kavunda istenen bir özelliktir. Bu özellik açısından, en küçük çekirdek evi çap1 $(6.14 \mathrm{~cm})$ Ares F1 üzerine aşılanan Sinem $45 \quad F_{1}$ çeşidinin kavun meyvelerinde saptanırken; en büyük çekirdek evi çap1 $(8.28 \mathrm{~cm})$ Sürmeli F1 çeşidinin aşısız bitkilerinden alınan meyvelerden elde edilmiştir (Çizelge 4). En yüksek çekirdek evi yükssekliği $(22.67 \mathrm{~cm}, 22.44 \mathrm{~cm}), \mathrm{TZ} 148 \mathrm{~F} 1$ ve Ares F1 anac1 üzerine aş1lı Sinem 45 F1 çeşidinden elde edilirken, en düşük çekirdek evi yüksekliği $(13.30,13.50,13.41$ ve $14.26 \mathrm{~cm})$ Sürmeli $F_{1}$ çeşidinin aşılı ve aşısız bitkilerinden alınan meyvelerde kaydedilmiştir. (Çizelge 5). 


\section{Farklı Anaçlar Üzerine Aşılanan Kırkağaç Kavunlarının Meyve Özelliklerinin Araştırılması}

Çizelge 4. Farklı anaçlar üzerine aşılanan Sinem $45 F_{1}$ ve Sürmeli $F_{1}$ çeşitlerinin ortalama çekirdek evi çapı $(\mathrm{cm})$

\begin{tabular}{|c|c|c|c|}
\hline \multirow[t]{2}{*}{ Anaçlar } & \multicolumn{2}{|c|}{ Çeşitler } & \multirow{2}{*}{$\begin{array}{l}\text { Anaç } \\
\text { Ort. }\end{array}$} \\
\hline & $\begin{array}{l}\text { Sinem } \\
45 \mathrm{~F} 1\end{array}$ & $\begin{array}{l}\text { Sürmeli } \\
\text { F1 }\end{array}$ & \\
\hline Ares F1 & $6.14 \mathrm{e}$ & $7.28 \mathrm{~b}$ & $6.71 \mathrm{~B}$ \\
\hline $\begin{array}{ll}\text { Nun } & 9075 \\
\text { F1 } & \\
\end{array}$ & $7.10 \mathrm{bc}$ & $6.69 \mathrm{~cd}$ & $6.89 \mathrm{~B}$ \\
\hline TZ $148 \mathrm{~F} 1$ & $6.46 \mathrm{de}$ & $7.13 b$ & $6.79 \mathrm{~B}$ \\
\hline $\begin{array}{l}\text { Aşısız } \\
\text { (Kontrol) }\end{array}$ & $7.23 \mathrm{~b}$ & $8.28 \mathrm{a}$ & $7.76 \mathrm{~A}$ \\
\hline Çeşit Ort. & $6.73 \mathrm{~B}$ & $7.34 \mathrm{~A}$ & \\
\hline
\end{tabular}

ÖD: Önemli değil; *: 0.05 düzeyinde; **: 0.01 düzeyinde; $* * *$ : ise 0.001 düzeyinde LSD karşılaştırmasına göre farklılığı göstermektedir.

Çizelge 5. Farklı anaçlar üzerine aşılanan Sinem 45 F1 ve Sürmeli F1 çeşitlerinin ortalama çekirdek evi yüksekliği $(\mathrm{cm})$

\begin{tabular}{|l|l|l|l|}
\hline \multirow{2}{*}{ Anaçlar } & \multicolumn{2}{|c|}{ Çeşitler } & \multirow{2}{*}{$\begin{array}{l}\text { Anaç } \\
\text { Ort. }\end{array}$} \\
\cline { 2 - 4 } & $\begin{array}{l}\text { Sinem } \\
45 \mathrm{~F} 1\end{array}$ & $\begin{array}{l}\text { Sürmeli } \\
\mathrm{F} 1\end{array}$ & \\
\hline Ares F1 & $22.44 \mathrm{a}$ & $14.26 \mathrm{c}$ & $18.35 \mathrm{~A}$ \\
\hline Nun 9075 F1 & $20.00 \mathrm{~b}$ & $13.41 \mathrm{c}$ & $16.71 \mathrm{~B}$ \\
\hline TZ 148 F1 & $22.67 \mathrm{a}$ & $13.50 \mathrm{c}$ & $18.08 \mathrm{~A}$ \\
\hline $\begin{array}{l}\text { Aş1S1Z } \\
\text { (Kontrol) }\end{array}$ & $19.28 \mathrm{~b}$ & $13.30 \mathrm{c}$ & $16.29 \mathrm{~B}$ \\
\hline Çeşit Ort. & $21.10 \mathrm{~A}$ & $13.62 \mathrm{~B}$ & \\
\hline $\begin{array}{l}\text { Anaç: } 0.72^{* * *} \\
\text { Anaç } \times \text { Kalem: } 1.01^{* *} \text { Kalem: } 0.51^{* * *}\end{array}$ \\
\hline
\end{tabular}

$\mathrm{P} \leq 0,001^{* * *}, \mathrm{P} \leq 0,01 * *, \mathrm{P} \leq 0,05^{*}$ düzeyinde LSD

karşılaştırmasına göre farklılı̆̆ 1 göstermektedir.

Çizelge 6'da anaç uygulamalarının iki çeşitte meyve et kalınlığ 1 üzerine etkisi gösterilmiş̧ir. Anaç ve kalem istatistiksel olarak önemli bulunurken, anaç x çeşit interaksiyonları önemli bulunmamıştır. Meyve eti kalınlıkları, 4.17-5.62 $\mathrm{cm}$ arasında değişmiştir. Sinem $45 \mathrm{~F} 1$ çeşidi $(4.78 \mathrm{~cm})$, Sürmeli F1 çeşidinden $(4.44 \mathrm{~cm})$ daha yüksek değere sahip olmuştur. Anaç uygulamaları kavun çeşitlerinde kabuk kalınlığ üzerine etki göstermiş; en kalın kabuk $13.61 \mathrm{~mm}$ ile Ares F1 üzerine aşılanan Sinem 45 çeşidinden elde edilirken, en ince kabuk ise $8.25 \mathrm{~mm}$ ile Ares $F 1$ üzerine aş1lı Sürmeli $F$ 1 çeşidinde kaydedilmiştir edilmiştir (Çizelge 7).
Çizelge 6. Farklı anaçlar üzerine aşılanan Sinem $45 F_{1}$ ve Sürmeli F1 çeşitlerinin ortalama meyve eti kalınlı̆̆ $1(\mathrm{~cm})$

\begin{tabular}{|l|l|l|l|}
\hline \multirow{2}{*}{ Anaçlar } & \multicolumn{2}{|c|}{ Çeşitler } & Anaç \\
\cline { 2 - 4 } & $\begin{array}{l}\text { Sinem } \\
\text { 45 F1 }\end{array}$ & $\begin{array}{l}\text { Sürmeli } \\
\text { F1 }\end{array}$ & \\
\hline Ores F1 & 4.61 & 4.32 & $4.47 \mathrm{~B}$ \\
\hline Nun 9075 F1 & 4.32 & 4.17 & $4.24 \mathrm{~B}$ \\
\hline TZ 148 F1 & 4.56 & 4.25 & $4.40 \mathrm{~B}$ \\
\hline $\begin{array}{l}\text { Aş1s1z } \\
\text { (Kontrol) }\end{array}$ & 5.62 & 5.03 & $5.33 \mathrm{~A}$ \\
\hline Çeşit Ort. & $4.78 \mathrm{~A}$ & $4.44 \mathrm{~B}$ & \\
\hline $\begin{array}{l}\text { Anaç: } 0.37^{* * *} \text { Kalem: } 0.26^{*} \\
\text { Anaç } \times \text { Kalem: ÖD }\end{array}$ \\
\hline
\end{tabular}

karşılaştırmasına göre farklılığı göstermektedir.

Çizelge 7. Farklı anaçlar üzerine aşılanan Sinem $45 \mathrm{~F} 1$ ve Sürmeli F1 çeşitlerinin ortalama meyve kabuk kalınlığ $1(\mathrm{~mm})$

\begin{tabular}{|l|l|l|l|}
\hline \multirow{2}{*}{ Anaçlar } & \multicolumn{2}{|c|}{ Çeşitler } & Anaç \\
\cline { 2 - 4 } & $\begin{array}{l}\text { Sinem } \\
45 \mathrm{~F} 1\end{array}$ & $\begin{array}{l}\text { Sürmeli } \\
\text { F1 }\end{array}$ & \\
\hline Ort.
\end{tabular}

$\mathrm{P} \leq 0,001^{* * *}, \mathrm{P} \leq 0,01^{* *}, \mathrm{P} \leq 0,05^{*}$ düzeyinde LSD karşılaştırmasına göre farklılığı göstermektedir.

Anaç ve kalemin uyuşumunun zayıf olması sonucunda fizikokimyasal meyve kalitesi, depo ömrü ve besin içeriği aşılamadan etkilenebilir (Kyriacou ve ark., 2017). Kavunda şeker içeriğinin yüksek olması, istenilen bir özelliktir. Şeker içeriğinin belirlenmesinde çeşitli analizler yapılmakla birlikte, refraktometrik SÇKM ölçümleri de bu parametre açısından önemli derecede fikir verebilmektedir. Brix değerlerinde kavun için 9 Brix "iyi iç kalite" ve 11 Brix "çok iyi iç kalite" olarak kabul edilmektedir (USDA, 2008). Meyvede depolanan şekerler solunum işlemi sırasında kullanılabildiğinden, bu yüksek değerler daha 


\section{Farklı Anaçlar Üzerine Aşılanan Kırkağaç Kavunlarının Meyve Özelliklerinin Araştırılması}

uzun bir raf ömrüne yol açabilir (Olguin ve ark., 2020). SÇKM oranı en fazla aşısız kontrol Sinem $45 F_{1}$ ve Sürmeli $F_{1}$ çeşitlerinden (\%10.24, \%9.87) ve Ares F1 çeşidi üzerine aş11 Sürmeli F1 çeşidinden (\%9.97) alınmıştır. Bununla birlikte en düşük SÇKM değerleri, Nun $9075 F_{1}$ anac1 üzerine aş11 Sürmeli $F_{1}$ ve Sinem $45 \mathrm{~F} 1$ çeşidinden $(\% 6.88, \% 7.65)$ ve $\mathrm{TZ} 148 \mathrm{~F} 1$ anacı üzerine aş1lı Sürmeli $F_{1}$ çeşidinden (\%7.58) alınmıştır (Çizelge 8).

Çizelge 8. Farklı anaçlar üzerine aşılanan Sinem $45 \mathrm{~F}_{1}$ ve Sürmeli F1 çeşitlerinin ortalama SÇKM (\%) değeri

\begin{tabular}{|c|c|c|c|}
\hline \multirow[t]{2}{*}{ Anaçlar } & \multicolumn{2}{|c|}{ Çeşitler } & \multirow{2}{*}{$\begin{array}{l}\text { Anaç } \\
\text { Ort. }\end{array}$} \\
\hline & $\begin{array}{l}\text { Sinem } \\
45 \mathrm{~F}_{1}\end{array}$ & $\begin{array}{l}\text { Sürmeli } \\
\text { F1 }\end{array}$ & \\
\hline Ares $F_{1}$ & $9.08 \mathrm{~b}$ & $9.97 \mathrm{a}$ & $9.52 \mathrm{~B}$ \\
\hline Nun $9075 F_{1}$ & $7.65 \mathrm{c}$ & $6.88 \mathrm{~d}$ & $7.26 \mathrm{D}$ \\
\hline TZ $148 \mathrm{~F}_{1}$ & $8.52 \mathrm{~b}$ & $7.58 \mathrm{c}$ & $8.05 \mathrm{C}$ \\
\hline $\begin{array}{l}\text { Aşısız } \\
\text { (Kontrol) }\end{array}$ & $10.24 \mathrm{a}$ & $9.87 \mathrm{a}$ & $10.06 \mathrm{~A}$ \\
\hline Çeșit Ort. & 8.87 & 8.57 & \\
\hline $\begin{array}{l}\text { Anaç: } 0.48^{* *} \\
\text { Anaç } \times \text { Kaler }\end{array}$ & $\begin{array}{l}\text { Kalem: } \\
0.67 * *\end{array}$ & & \\
\hline
\end{tabular}

\section{Sonuç ve Öneriler}

Yetiştirilen ürünün kalitesi; genetik, iklimsel, kültürel ve hasat sonrası faktörlerin etkileşimine bağlıdır. Kaliteyi en üst seviyeye çıkarmak için bu etkenlerin en iyi kombinasyonlarmı belirlemek gerekmektedir. $\mathrm{Bu}$ anlamda aşılamada özel anaçların kullanılması önemli bir rol oynamaktadır. Belirli bir kalem için uygun anaç seçimi optimum verim için olduğu kadar meyve kalitesi için de çok önemlidir. Bu nedenle, toprak kaynaklı hastalıkların daha iyi yönetilmesi ve abiyotik stres toleransının iyileştirilmesi olasılığının yanı sıra aşılama, meyve kalitesinin iyileştirilmesi için de önemli bir araç olabilir. $\mathrm{Bu}$ çalışma kavun yetiştiriciliğinde aş1lı fide kullanımının; bitkisel özellikler ve meyve özellikleri bakımından olumlu etkiler meydana getirdiğini ortaya koymuştur.

\section{Teșekkür}

$\mathrm{Bu}$ çalışmayı maddi olarak destekleyen, Çukurova Üniversitesi Bilimsel Araştırma
Projeleri Birimine (FYL-2018-10718) teşekkür ederiz.

\section{Kaynaklar}

Cohen R, Tyutyunik J, Fallik E, Oka Y, Tadmor Y, Edelstein, M. (2014) Phytopatological evaluation of Eexotic watermelon germplasm as a basis for rootstock breeding Sci Hort 165:203210.

Colla, G., Rouphael, Y., Cardarelli, M., Massa, D., Salerno, A., Rea, E. (2006) Yield, fruit quality and mineral composition of grafted melon plants grown under saline conditions. J Hort Sci Biotechnol 81:146-152.

Cushman, K. E. Huan, J. (2008) Performance of four triploid watermelon cultivars grafted onto five rootstock genotypes: yield and fruit quality under commercial growingconditions. Acta Horticulturae 782: 335-337.

Davis, A. R., Perkins-Veazie, P., Hassell, R., Levi, A., King, S.R. Zhang, X. (2008) Grafting effects on vegetable quality. HortScience 43:1670-1672.

Den Nijs, A. P. M. (1984) Rootstock-scion interactions in the cucumber, implations for cultivaon and breeding. Acta Horticulturae 156:53-60.

FAO, (2020.) Year melon production http://www.fao.org/faostat/en/\#data/QC

Gaion, L. A., Braz, L. T., Carvalho, R. F. (2018) Grafting in vegetable crops: a great technique for agriculture. International Journal of Vegetable Science 24: 85102.

Guan, W., X. Zhao, D.J. Huber. (2015) Grafting with an interspecific hybrid squash rootstock accelerate fruit development and impaired fruit quality of galiamelon. HortScience 50:1833-1836.

Huitrón, M.V., Diaz, M., Dianez, F. Camacho, F. (2007) The effect of various rootstocks on triploid watermelon yield and qualify. Journal of Food, Agriculture and Environment 5:344348.

Jang, Y., Y. C. Huh, D. K. Park, B. Mun, S. Lee, Y. Um. (2014) Greenhouse evaluation of 


\section{Farklı Anaçlar Üzerine Aşılanan Kırkağaç Kavunlarının Meyve Özelliklerinin Araştırılması}

melon rootstock resistance to monosporascus root rot and vine decline as well as of yield and fruit quality in grafted "1nodorus", melons. Kor J Soc Hort Sci, 32(5):614-622.

Karabulut, A., Aktaş, H., Şan, B. (2018) Sera kavun yetiştiriciliğinde aşılı fide kullanımının verim ve kaliteye etkileri. Süleyman Demirel Üniversitesi Fen Bilimleri Enstitüsü Dergisi Cilt 22 (3): 1223-1231.

Kyriacou, M. C., Rouphael, Y., Colla, G., Zrenner, R., Schwarz, D. (2017) Vegetable grafting: the implications of a growing agronomic imperative for vegetable fruit quality and nutritive value. Front Plant Sci 8:741. doi: 10.3389/ fpls.2017.00741

Mancak, I., Sarı, N., Solmaz, I., Ozkan, H. (2014) Determining the relationships between kirkagac and other melon types by using morphological and molecular methods. Cucurbitaceae 2014 Proceedings, 80-83.

Nisini, P.T., Colla, G., Granati, E., Temperini, O., Crin_O, P., Saccardo, F. (2002) Rootstock resistance to fusarium wilt and effect on fruit yield and quality of two muskmelon cultivars. Sci Hort 93(34):281-288.

Olguin, M. A. V., Fuente, M. C., Mendoza, A. B., Maldonado, A. J., Rangel, A. S., Cusimamani, E. F. (2020) Commercial and nutraceutical quality of grafted melon cultivated under hydric stress. Horticultural Science (Prague), 47 (3): 139-149.

Özarslandan, A., Söğüt, M. A., Yetişir, H., Elekçioğlu, İ.H. (2011) Screening of bottle gourds (lagenaria siceraria (molina) standley) genotypes with rootstock potential for watermelon production for resistance against meloidogyne incognita (Kofoid \& White, 1919) chitwood and meloidogyne javanica (Treub, 1885). Chitwood. Turkish J Entomol 35(4):687-697.

Pitrat, M. (2008) Melon. In: Prohens J., Nuez F. (Eds.) Handbook of plant breeding.
Vegetables I. Asteraceae, Brassicaceae, Chenopoidicaceae, and Cucurbitaceae. Springer, USA, pp. 283- 315.

Rouphael, Y., D. Schwarz, A. Krumbein, G. Colla. (2010) Impact of grafting on product quality of fruit vegetables. Sci Hort, 127(2):172-179.

Rouphael, Y., Kyriacou, M. C., Colla, G. (2018) Vegetable grafting: a toolbox for securing yield stability under multiple stress conditions. Front. Plant Sci 8:2255. doi: 10.3389/fpls.2017.02255.

Soteriou, G.A., Kyriacou, M.C., Siomos, A.S., Gerasopoulos, D. (2014) Evolution of watermelon fruit physicochemical and phytochemical composition during ripening as affected by grafting. Food Chem, 165:282-289.

Soteriou, G.A., Papayiannis, L.C., Kyriacou, M.C. (2016) Indexing melon physiological decline to fruit quality and vine morphometric parameters. Sci Hort, 203:207-215.

Soteriou, G.A., Siomos, A.S., Gerasopoulos, D., Rouphael, Y., Georgiadou, S., Kyriacou, M.C. (2017) Biochemical and histological contributions to textural changes in watermelon fruit modulated by grafting. Food Chemistry 237: 133140.

Şensoy, S.(2005) Türkiye kavunlarındaki genetik varyasyonun ve fusarium solgunluğuna dayanıklılığın fenotipik ve moleküler yöntemlerle araştırılması. Doktora Tezi, Yüzüncü Y1l Üniversitesi Fen Bilimleri Enstitüsü Bahçe Bitkileri Anabilim Dal1, 164 S, Van.

USDA, (2008) United States standards for grades of cantaloupes. Agricultural Marketing Service, 1-6. United States Department of Agriculture. Available at https://www.ams.usda.gov/gradesstandards/cantaloup-grades-andstandards

Verzera, A., Dima, G., Tripodi, G., Condurso, C., Crino, P., Romano, D., Mazzaglia, A., Lanza, C.M., Restuccia, C., Paratore, A. (2014) Aroma and sensory quality of honeydew melon fruits (cucumis melo L. subsp. melo var. 


\section{Farklı Anaçlar Üzerine Aşılanan Kırkağaç Kavunlarının Meyve Özelliklerinin Araştırılması}

inodorus $\mathrm{H}$. jacq.) in relation to different rootstocks. SciHort 169:118-124.

Yetisir, H., Sari, N. (2003) Effect of different rootstock on plant growth, yield and quality of watermelon. Australian Journal of Experimental Agriculture 43, 1269-1274.

Yetişir, H., Sarı N., Yücel, S. (2003) Rootstock resistance to fusarium wilt and effect on watermelon fruit yield and quality. Phytoparasitica31(2):163-169.

Zhao, X., Guo, Y., Huber, D.J., Lee, J. (2011) Grafting effects on postharvest ripening and quality of 1-methylcyclopropenetreatedmuskmelon fruit. Sci Hort 130(3):581-587. 